\title{
Producción, comercio y potencialidades de la mora colombiana en el mercado internacional
}

pags $66-76$

Grupo de Investigación: Desarrollo y equidad - Centro de Investigación y competitividad empresarial Línea de investigación: Economía internacional - negocios internacionales e integración económica Gustavo Sandoval• \& Esperanza Bonillaø•

Recibido: 5 de junio de 2015

\section{RESUMEN}

Mediante este artículo, se explora la situación de la producción de mora en Colombia, su comercio en mercados extranjeros, y las posibilidades que le ofrece el mercado internacional, para incrementar sus exportaciones. Entre las más importantes, se concluye que la mora de castilla producida en Colombia, presenta características de uso terapéutico como un atractivo para destinos en el exterior. Además, que su producción ha crecido sustancialmente en los últimos veinte años. También, que los destinos más relevantes en el exterior son Panamá, Antillas Holandesas y Aruba; y que Europa, particularmente España, es un mercado potencial importante para este producto.

Palabras claves: Producción mora Colombia, comercio internacional mora, ventajas comparativas

Clasificación JEL: F1, F2

\section{ABSTRACT}

Through this article, are explored the production situation of in Colombia, their trade in foreign markets, and the possibilities offered by the international one, to increase their exports. Among the most important, it is concluded that the Castile blackberry produced in Colombia, has therapeutical characteristics usable as an attraction for foreign destinations. In addition, its production has grown substantially in the last twenty years. Also, the most important destinations abroad are Panama, Netherlands Antilles and Aruba; and that Europe, particularly Spain, is an important potential market for this product.

Key words: Production mora Colombia, international trade mora, comparative advantages

JEL classification: F1, F2

\section{INTRODUCCION}

El presente trabajo explora las posibilidades que tienen los productores de mora Colombianos para aumentar la exportación del producto a los mercados extranjeros. El interés en el tema surge porque la mora es un producto de cultivo tradicional en el país y su volumen de producción ha crecido considerablemente en los últimos años, además que la variedad de mora colombiana es muy valorada por sus características desde el punto de vista de su aporte a la salud del ser humano.

\footnotetext{
- MSc Economía. Universidad Nacional. Docente investigador Fundación Universidad de América. gustavo.sandoval@investigadores.uamerica.edu.co

•- Docente investigadora Fundación Universidad de América. esperanza.bonilla@investigadores.uamerica.edu.co
} 
El objetivo del trabajo es ampliar el conocimiento de la situación del mercado internacional de la mora, con el fin de que la investigación propuesta arroje como resultado un conocimiento más amplio a los productores de mora colombianos respecto a las expectativas que pueden tener para ampliar su negocio de comercialización hacia los mercados extranjeros.

\section{REFERENCIAS TEÓRICAS Y CONCEPTUALES}

Pensar en la inserción de productos en el mercado internacional, desde el ámbito académico, implica tomar algunos referentes teóricos, y dar luces sobre el porqué del valor analítico de dichos referentes. En este sentido, es pertinente hacer mención a las teorias clásica neoclásica, de las ventajas comparativas (Absolutas, en A. Smith; y Relativas, en D. Ricardo), neoclásica Heckscher y Ohlin,(1933), teoría de la integración (Jan Tinbergen, 1968; Bela Balasa, 1.974).

Entre Smith y Ricardo, se dan coincidencias en cuanto a que ambos plantean que se deben exportar aquellos bienes producidos con mayor eficiencia, asociando esta categoría con buenos niveles de productividad, y menores costos comparativos de producción. De este razonamiento, coligen que el comercio internacional estimula la especialización, lo cual redunda en mejoramiento de la productividad y acentúa la división internación al del trabajo

Adam Smith en la Riqueza de las Naciones expresa: "Siempre será máxima constante de cualquier prudente padre de familia no hacer en casa lo que cuesta más caro que comprarlo". (Smith 1958, 402-403). Haciendo extensivo este racionamiento al comercio internacional, para este autor, los países deben exportar aquellos bienes que para su producción requieran menos incorporación de trabajo ${ }^{1}$ que otros e importar

1 Recuérdese que en la teoría clásica de Smith y Ricardo el valor de las mercancías depende de las horas/hombre de trabajo incorporadas en la producción, por unidad de bien. aquellos bienes en cuya producción requieren más trabajo que otra u otras naciones, esta situación la denominó como ventaja absoluta.

Especialmente, en las relaciones que se establecen entre los países centrales y períféricos, para unos y/o desarrollados y en vías de desarrollo para otros, se considera que en ciertos contextos y para ciertos bienes transables en el comercio internacional, la teoría clásica sigue siendo el soporte teórico explicativo de la dinámica de la internacionalización de las economías, particularmente desde la óptica ricardiana y su concepto de la ventaja comparativa relativa.

La diferencia fundamental entre los postulados de Smith y de Ricardo, radica en que este último refutó la aseveración hecha por Smith, de que solamente quienes tuvieran ventaja comparativa absoluta, podrian participar en el comercio internacional y derivar ventajas de él.

Según Ricardo, los paises solamente necesitan tener ventajas comparativas relativas, para participar en los mercados mundiales con beneficios.

En efecto, Ricardo expuso que aunque un país tenga desventaja absolutas, le convendrá exportar aquel bien o bienes en los que su desventaja sea menor e importar aquel bien o bienes en cuya producción sea relativamente menos eficiente. Consecuente con este planteamiento, se le brinda a los países la opción de especializarse en la producción de aquel o aquellos bienes, en los cuales tenga ventaja comparativa relativa; convirtiéndose ésta, desde la mirada ricardiana, en el pilar que orienta la producción de un país hacia los mercados externos.

Para que se entienda más claramente su planteamiento, en su libro Principios de Economía Poltica y tributación (1.817), Ricardo utiliza un ejemplo referido a la producción de vinos y de tejidos. Suponemos que Portugal produce más barato tanto el vino como los tejidos. La clave radica en la especialización de cada país en la 
producción más competitiva en términos relativos, no absolutos. Como Portugal es más competitivo en vino, le conviene especializarse en su producción y comprar los tejidos de Inglaterra, aunque podría producirlos localmente a mejor precio. Portugal obtiene más beneficios con el margen que obtiene produciendo vino que si su economía produjera vino y tejidos, porque en los tejidos es menos competitivo relativamente.

Ricardo, al igual que Smith, le da primordial importancia a la productividad del trabajo como motor de la ventaja comparativa relativa y plantea que la diferencia en la productividad del trabajo, se traduce en costos y precios comparativos relativos diferentes. En consecuencia, prácticamente ningún país quedaría excluido de participar en el comercio internacional y de derivar beneficios de él, lo cual redunda en el aumento de su producción y de su consumo internos.

Por su parte, los neoclásicos Heckscher y Ohlin,(1933) soportan su conceptualización de la ventaja comparativa en los siguientes postulados.

a. Cuando en la producción de un bien se utiliza el factor abundante del que dispone un país, esta circunstancia le confiere ventaja comparativa, en términos de costos de producción, y b. Que el comercio entre los países de destino y origen debe ser de libre acceso, es decir sin ningún tipo de restricciones, lo cual hoy día se refleja en los tratados de libre comercio.

La integración concebida, desde la óptica de libertad de comercio global, fue propuesta por Jan Tinbergen (1968), premio Nobel de Economía. El autor publicó su libro en 1.954, "Hacia una economía mundial", asociando ese concepto con el del libre comercio de productos, tanto industriales como agropecuarios, y la define como: "(...) la creación de la estructura más deseable de la economía internacional, mediante la remoción de los obstáculos artificiales a su operación óptima y la introducción deliberada de todos los elementos deseables de coordinación y de unificación"
Otro autor muy conocido y citado, cuando de hacer referencia a la integración se trata, es Bela Balassa (1974) quien define la integración como: "El estado de cosas por las cuales diferentes regiones deciden formar un grupo regional". Según el autor, este proceso comprende varios niveles, empezando por la consolidación de zonas de libre comercio y uniones aduaneras, pasando por mercados comunes y uniones monetarias, y políticas. En este proceso, hay un común denominador y es, a partir del primer nivel (zona de libre comercio), se trata de acabar con restricciones comerciales particularmente arancelarias. En este contexto, cualquier acuerdo o negociación que establezca preferencias $y / o$ termine con restricciones al comercio, entre los países que lo instituyen, se convierte en un espacio de oportunidades para intercambios comerciales externos. Dicho en otros términos, cuanto más libre sea el proceso, mayores son las oportunidades de satisfacer el consumo por parte de habitantes de diferentes países. Sin embargo, no se debe asumir que "integración" implica como objetivo fundamental liberalizar el comercio. Este concepto, de manera mucho más amplia, implica apertura a la inversión extranjera; profundizar la especialización y la complementación de actividades económicas, industriales y agrícolas, que coadyuven al desarrollo de los paises. No ha de creerse que el comercio per- se, genera desarrollo.

Si bien es cierto que por efecto de la profundización de la globalización, el contexto de las relaciones internacionales comerciales, ha cambiado sustancialmente con relación al que imperaba cuando salieron a luz las teorías expuestas en este artículo, en el caso específico de las condiciones de producción de la mora colombiana y sus potencialidades para los mercados externos, dichas teorías sirven de soporte analítico.

Las siguientes características sustentan la anterior afirmación.

1. La oferta productiva de la mora, se inserta en condiciones que se asemejan a la competencia perfecta. 
LÍNEA DE INVESTIGACIÓN: ECONOMIA INTERNACIONAL - NEGOCIOS INTERNACIONALES

2. Este es un producto que en sus procesos de producción utiliza más intensivamente mano de obra.

3. Los TLC, pueden convertirse en un espacio que le dé oportunidades de mercado al producto, toda vez que en los acuerdos negociados, las frutas y verduras quedaron con desgravación inmediata.

4. Los procesos de integración en el marco de libertad de comercio como lo plantea Tinberger, y de la conformación de grupos regionales de integración, que supriman barreras comerciales entre los países que lo conformen, estilo Bela Balassa, pueden proporcionar oportunidades a la mora en mercados internacionales, diferentes a EE.UU. y la Unión Europea.

\section{MÉTODO}

Principales Variedades de mora producidas en Colombia

En Colombia se cultiva un amplio número de especies y variedades de mora, principalmente del género Rubus y particularmente de la variedad glaucus Benth. Según Aguilar (2006, citado por Espinoza, 2011, pág. 27) en diversas regiones del país se encuentran variedades del:

"(...) taxa bogotensis HBK, sembrada en altitudes entre los 1700 y los $3700 \mathrm{msnm}$; $R$ giganteus o macrocarpus Benth, entre los 2600 y los $3400 \mathrm{msnm}$; $R$. megalococcus Focke, entre los 2300 y los $2700 \mathrm{msnm}$ y $R$. nubigeus ( $R$. macrocarpus, Romoleroux, 1996), entre los 2600 y los 3100 msnm".

La variedad Rubus glaucus Benth corresponde a la especie más conocida en el medio nacional, con el nombre de mora de castilla. De acuerdo a Espinoza (2011, pag.7):

"(...) Las especies Rubus primarias pudieron haber llegado a Colombia hace 4,5 o 3,5 millones de años durante el Pleistoceno, una vez se consolidó la unión entre Suramérica y Centroamérica a través del Istmo de Panamá".

Las especies Rubus se han distinguido desde tiempos muy remotos, como frutos que poseen propiedades curativas, para diversas dolencias y enfermedades; habiendo sido utilizadas tradicionalmente en la medicina china, griega y americana, como lo refiere Patel et al. (2004, Citados por Espinoza, N. (2011). Ésta característica es un factor importante en la promoción comercial del producto a nivel internacional.

\section{Evolución de la producción de mora en Colombia}

La superficie sembrada con mora, y el volumen de producción en Colombia, ha venido creciendo consistentemente en los últimos veinte años. Como se observa en el cuadro 1 y la gráfica 1, el área cultivada y la producción de mora tuvo un crecimiento sostenido desde 1992 hasta 2013. En este periodo, la producción total del país pasó de 22.476 tons en el año 1992, a una producción de 105.285 tons en el año 2013; en tanto el área cosechada pasó en el mismo periodo de 275 hectáreas a 1.220 hectáreas. La productividad por hectárea se comportó de manera irregular en el periodo señalado. Mientras en 1992, se obtuvo una productividad promedio en el país de 7.1 tons por hectárea (12.2 tons. por hectárea en Antioquia, la máxima alcanzada en ese año), en 2013 subió a un promedio nacional de 8.8 tons por hectárea.

De acuerdo a los análisis de las potencialidades de productividad para los cultivos de mora en Colombia, se alcanzó una de 23,8 y 20,8 tons/ha. con y sin espinas, en condiciones de laboratorio. Franco y Giraldo (1998) afirman que un cultivo bien manejado, en condiciones de cultivo comercial en Colombia, puede llegar a producir de 18 a 20 ton/ha. (Citado por Grijalba, C. et al., 2010, pag.29).

Desde el punto de vista de la distribución geográfica de la producción, varió sensiblemen- 
te en el periodo ya señalado. En primer lugar se ha ampliado el número de departamentos donde se produce el producto, pasando de 13 departamentos en 1992, a 16 departamentos productores en 2013.

De otra parte, la importancia relativa de cada departamento, ha tenido variaciones sensibles en la producción nacional. El mayor productor, tanto en 1992 como en 2013, fue el departamento de Cundinamarca, cuadruplicando el volumen de producción, pasando de 6.566 tons producidas en 1992 , a 25,099 en 2013 . Un repunte más notable aún fue el de Santander, donde se produjeron 2.115 tons en 1992, y donde se multiplicó la producción por diez, al lograr producir 21.142 tons para 2013. También, el crecimiento fue apreciable en Antioquia, donde su producción se multiplicó por cuatro entre los dos periodos considerados. Otros departamentos donde el volumen de producción creció de manera notable, fueron Boyacá, Caldas, Nariño, Meta, Cauca, Cesar y Risaralda.

Cuadro 1. Producción de mora, área cosechada y rendimiento por Hectárea por departamentos $1992 / 2013$

\begin{tabular}{|c|c|c|c|c|}
\hline Departamento & $\begin{array}{c}\text { Area Cosech. } \\
\text { (Has) }\end{array}$ & $\begin{array}{c}\text { Producción } \\
\text { (Tons) }\end{array}$ & $\begin{array}{c}\text { Rendimiento } \\
\text { (Tons/Ha) }\end{array}$ & $\begin{array}{l}\text { Participación } \\
\text { producción } \\
\text { nacional }(\%)\end{array}$ \\
\hline \multicolumn{5}{|c|}{1992} \\
\hline Antioquia & 275 & 3.365 & 12.2 & 14.93 \\
\hline Boyacá & 101 & 724 & 7.2 & 3.22 \\
\hline Caldas & 68 & 773 & 11.4 & 3.44 \\
\hline Cauca & 17 & 53 & 3.1 & 0.24 \\
\hline Cesar & 4 & 32 & 8.0 & 0.14 \\
\hline Cundinamarca & 847 & 6.566 & 7.8 & 29.21 \\
\hline V. del Cauca & 1.062 & 3.194 & 3.0 & 14.21 \\
\hline Huila & 228 & 2.052 & 9.0 & 9.13 \\
\hline Meta & 19 & 190 & 10.0 & 0.85 \\
\hline Quindío & 41 & 203 & 5.0 & 0.90 \\
\hline Risaralda & 88 & 639 & 7.3 & 2.84 \\
\hline Santander & 245 & 2115 & 8.6 & 9.41 \\
\hline Tolima & 172 & 2.580 & 15 & 11.48 \\
\hline Total & 3.167 & 22.476 & 7.1 & 100.0 \\
\hline \multicolumn{5}{|c|}{2013} \\
\hline Antioquia & 1.220 & 14.676 & 12.0 & 13.94 \\
\hline Boyacá & 710 & 5.750 & 8.1 & 5.46 \\
\hline Caldas & 342 & 6.415 & 18.7 & 6.09 \\
\hline Cauca & 397 & 2.210 & 5.8 & 2.10 \\
\hline Cesar & 188 & 1.041 & 5.5 & 0.99 \\
\hline Cundinamarca & 3.192 & 25.099 & 7.9 & 23.84 \\
\hline Risaralda & 502 & 5.138 & 10.2 & 4.88 \\
\hline Santander & 1.886 & 21.142 & 11.2 & 20.08 \\
\hline Tolima & 597 & 4.555 & 7.6 & 4.33 \\
\hline V. del Cauca & 471 & 3.194 & 6.8 & 3.03 \\
\hline Putumayo & 9 & 18 & 2.0 & 0.02 \\
\hline
\end{tabular}


LINEA DE INVESTIGACIÓN: ECONOMIA INTERNACIONAL - NEGOCIOS INTERNACIONALES

\begin{tabular}{|l|c|c|c|c|}
\hline \multicolumn{1}{|c|}{ Departamento } & $\begin{array}{c}\text { Area Cosech. } \\
\text { (Has) }\end{array}$ & $\begin{array}{c}\text { Producción } \\
\text { (Tons) }\end{array}$ & $\begin{array}{c}\text { Rendimiento } \\
\text { (Tons/Ha) }\end{array}$ & $\begin{array}{c}\text { Participación } \\
\text { producción } \\
\text { nacional (\%) }\end{array}$ \\
\hline Chocó & 9 & 54 & 6.0 & 0.05 \\
\hline Huila & 991 & 6.920 & 7.0 & 6.57 \\
\hline Meta & 101 & 980 & 9.7 & 0.93 \\
\hline Nariño & 861 & 4.422 & 5.1 & 4.20 \\
\hline Nte. de Sant. & 396 & 3.217 & 8.1 & 3.06 \\
\hline Quindío & 116 & 455 & 3.9 & 0.43 \\
\hline Total & 11.986 & 105.285 & 8.8 & 100.0 \\
\hline
\end{tabular}

Fuente: Ministerio de Agricultura. Agronet.

Gráfica 1 - Área cosechada y producción de mora en Colombia 1992-2013

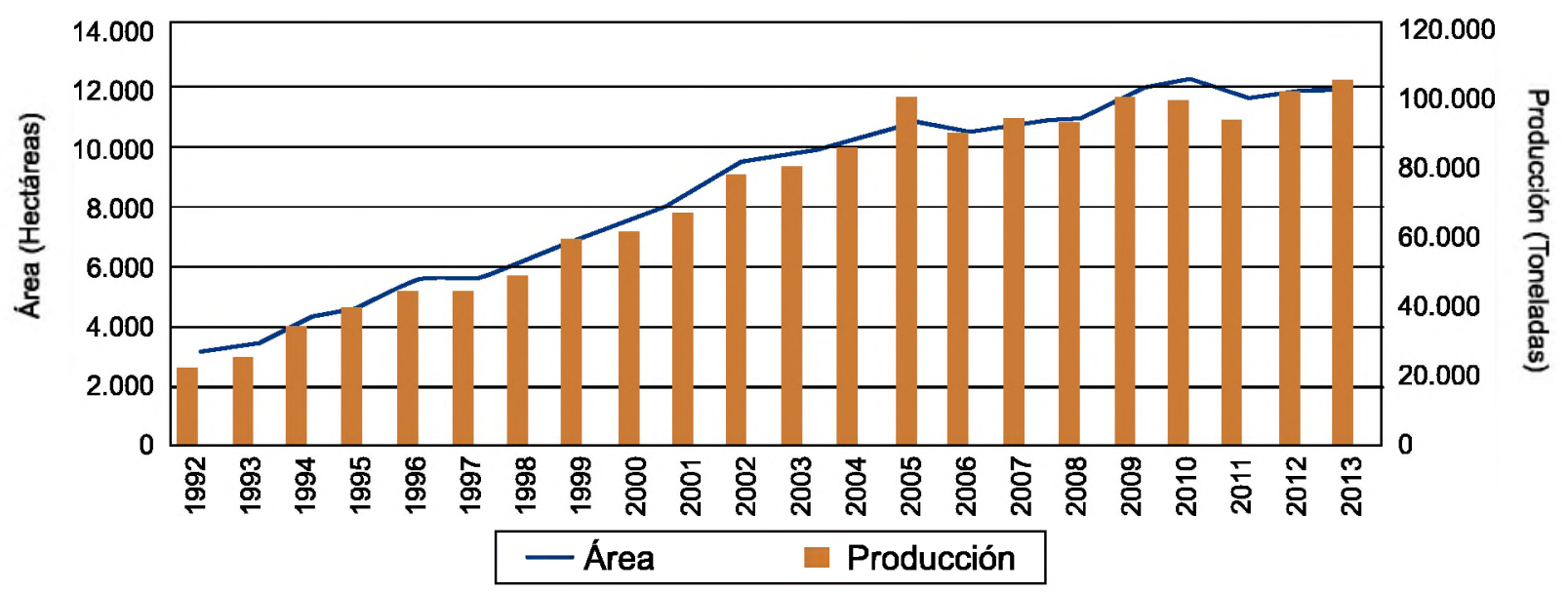

Fuente: Ministerio de Agricultura, Agronet.

\section{Oportunidades y limitaciones para la participación de la mora en el mercado internacional}

Hoy en día existe una tendencia al consumo de alimentos frescos, con predilección por los productos denominados orgánicos, ante todo en los países desarrollados, por sus efectos sobre la salud. Para Libreros (2013), citado por Villareal (2014):

"(...) la mora de castilla es apetecida por los beneficios que brinda, entre ellos: ayuda a proteger el organismo del envejecimiento prematuro de las diabetes, entre otras. Su consumo frecuente permite disminuir los niveles de grasa en las arterias y combatir la anemia.
La mora procesada tiene gran aceptación en el mercado exterior como concentrado y grandes posibilidades como materia prima en vinos, esencias y fruto congelado"

Y también como materia prima para helados, yogurt, lácteos saborizados, mermeladas y jugos, según Vidal y Loaiza (2004). Adicionalmente, de acuerdo con "El Journal of Terapéutica Food" (06/2007), las moras contienen una alta concentración de polifenoles o antioxidantes, que benefician positivamente a la salud de las personas, $y$ el extracto de mora disminuye el crecimiento de ciertos tipos de células tumorales.

El investigador J. Dai (2007), concluyó: “que el extracto de mora puede ser un potencial tra- 
tamiento para el cáncer que ayude a combatirlo de forma preventiva y también puede ayudar a prevenir otras enfermedades inflamatorias."

Los principales factores que influyen en la demanda de la fruta son: el sabor, la calidad y la apariencia. La tendencia es comprar porciones más pequeñas y listas para el consumo. Las campañas anti-comida chatarra despiertan simpatía y crece la importancia de la comida saludable, frutas en fresco y orgánicas.

Según estudios sobre la producción fruticola colombiana (Castro et al. 2012) "(...) se observa que existe un proceso de transición entre la transformación de cultivos tradicionales a cultivos orgánicos".

Ésta y otras circunstancias adicionales, tales como: la inclusión del sector hortofrutícola, como parte del programa de transformación productiva; y el acceso sin restricciones de los bienes provenientes de la horti-fruticultura colombiana, negociado en los tratados de libre comercio, hacen que se potencialice el crecimiento del sector. Se brindan así las oportunidades a las frutas colombianas en los mercados externos $y$, desde luego, al subsector productor de mora.

Entre las regiones productoras de mora en el país, la del Sumapaz (centro occidente colombiano) y la de la sabana de Bogotá, ofrecen mayor potencial, por las características de menor acidez.

Otras zonas productoras de mora de castiIla son: en el departamento de Cundinamarca, Zipacón, Venecia, Soacha, Granada, Silvania, Anolaima, La Florida y Cachipay. En el Tolima: Roncesvalles e Icononzo. En el Cauca: Caloto y Santander de Quilichao. Pitalito en el Huila. En el Valle: Tulúa, Ginebra, Trujillo, Jamundí y Restrepo. En Antioquia: La Ceja, Rionegro, Guarne y La Unión.

No obstante el potencial que ofrecen las regiones, los productores enfrentan problemas tales como: no disponer de canales adecuados de comercialización, debilidad en su organización, baja utilización de tecnología y mínima innovación, entre otros. Son aspectos que deben considerarse con prioridad, en el diseño de una estrategia concertada entre sector público y privado, para proporcionarle competitividad al subsector.

Según Villareal (óp. Cit.) la unión europea, particularmente España, ofrece condiciones de demanda favorables a este producto. Algunos estudios plantean que allí existe una demanda insatisfecha, y que el consumo de frutas frescas se ubica en el centro norte de España, especialmente entre las mujeres, convirtiéndose Bilbao en un centro importante de consumo.

La mora colombiana es demandada para la producción de refrescos y mermeladas, en el mercado de Estados Unidos, particularmente la que proviene de cultivos de la sabana de Bogotá.

Como ya se mencionó, existe una tendencia a consumir productos saludables en los mercados mundiales, y en consecuencia los consumidores inclinan sus preferencias por:

\footnotetext{
"Alimentos lavados, pre-cortados, empacados por porciones, para facilitar la preparación de las comidas.... Los principales factores que influyen en la compra de la fruta son el sabor, la calidad y la apariencia. La tendencia es comprar porciones más pequeñas y listas para el consumo. Las campañas anti-comida chatarra despiertan simpatía y crece la importancia de la comida saludable, frutas en fresco y orgánicas”. (CICO. 2008, pag.11).
}

De manera general, Villareal (óp. Cit.) hace referencia a ciertos requisitos exigidos por la European Commission, para exportar a la Unión Europea productos alimenticios, contenidos en el Reglamento 178/2002 y el reglamento $852 / 2004$. Allí se encuentran las exigencias de calidad de los productos para el consumo humano, en cuanto a manejo e higiene, condiciones fitosanitarias, de embalaje y de etiqueta: 
LÍNEA DE INVESTIGACIÓN: ECONOMIA INTERNACIONAL - NEGOCIOS INTERNACIONALES

"(...) las directrices de la Unión Europea exigen que la presentación de un producto sea un etiquetado general. La información que debe ir en la etiqueta debe ser presentada en el idioma que puedan comprender los consumidores, considerando el idioma oficial donde va a llegar la mora de castilla, como preferencia la legislación de la UE da la posibilidad de que en la etiqueta pueda incluirse varios idiomas, para que el producto pueda ser reconocido en varios mercados de los diferentes países que integran la UE y de tal manera llegar a mayor número de consumidores. La información que se detalla en la etiqueta es el nombre del producto o nombre comercial, en caso de ser un producto elaborado se colocará la lista de ingredientes en orden descendente y con la respectiva cantidad, también se coloca la cantidad neta del contenido (peso, volumen), fecha de vencimiento, es importante colocar el nombre del fabricante, envasador o distribuidor, las instrucciones de uso y de su almacenamiento, identificación del lote y el país de origen. Según la Oficina Comercial de España (2013), el etiquetado está regulado por el Real Decreto 1334/1999, norma que es aplicada para los productos alimenticios a ser adquiridos por el consumidor final."

Es de anotar que el Sistema Generalizado de Preferencias (SGP) que otorga la unión europea a países en vías de desarrollo, o de menor desarrollo, permite ingresar a su territorio productos con cero aranceles, entre los cuales se encuentran los agrícolas.

\section{Comercio exterior de mora desde Colombia}

Las estadisticas de comercio exterior de mora colombiana, presentan dificultad para su cálculo, en cuanto no poseen una partida arancelaria para ese solo producto. Aparece en dos partidas donde se incluyen diferentes frutas. La partida: 0810200000, para frambuesas, zarzamoras, moras y moras-frambuesa, frescas; 0811200000: frambuesas, zarzamoras, moras, moras-frambuesa y grosellas (sin cocer o cocidas en agua 0 vapor, congeladas, incluso con adición de azúcar u otro edulcorante y grosellas).
Dentro de estas partidas, la mora es el producto más representativo en el comercio de exportación. $Y$ ya que por no estar discriminado, los volúmenes de exportación de dichas partidas constituyen una aproximación a su volumen de comercio.

De acuerdo con datos de la Cámara de Comercio de Bogotá:

"(...) en el 2013 las exportaciones de fre-
sas, frambuesas, zarzamoras y moras des-
de Colombia fueron de US\$ 387.516 , la
región Bogotá - Cundinamarca exportó el
$82.7 \%$ (US $\$ 320.423$ ), de los cuales Bogo-
tá exportó US\$144.360 y Cundinamarca
US $\$ 176.063$. La región es la principal ex-
portadora de estos productos, seguida por
Antioquia (9.5\%) y Valle del Cauca ( $6.3 \%)$ ).

De estas cifras se puede deducir que las regiones productoras diferentes a Bogotá-Cundinamarca presentan dinamismo como exportadoras:

"Las exportaciones nacionales de fresas, frambuesas, zarzamoras y moras registraron un aumento de $18.9 \%$ con respecto al 2012 , cuando alcanzaron los US\$ 325.811. Las exportaciones del país se dirigieron principalmente a Panamá (44.5\%), Antillas Holandesas (22.5\%), Estados Unidos (17.9\%) y Aruba (8\%). Por su parte, las exportaciones de la región en este rubro aumentaron en $17.7 \%$ con respecto a 2012 (US\$ 272.229). $Y$ se concentraron en 4 mercados: Panamá $(53.8 \%)$, Antillas Holandesas (30.7\%), Aruba $(9.6 \%)$ y Estados Unidos (3.7\%)." (Cámara de Comercio de Bogotá. (2014).

La balanza comercial de Colombia, con respecto a la mora y los frutos conexos, resulta altamente deficitaria, como se deduce de la comparación entre exportaciones e importaciones. En efecto, para el año 2013, las importaciones totales de las partidas arancelarias en referencia, sumaron US\$606.704, lo cual arroja un déficit en la balanza comercial de US\$219.188 en las partidas. Representa un fuerte empeoramiento con respecto a lo que se presentó en 2012, cuando se obtuvo un superávit por US\$179.590. 
Gráfica 2. Exportaciones de Bogotá-Cundinamarca de fresas, frambuesas, zarzamoras y moras por destino - 2013 (US\$)

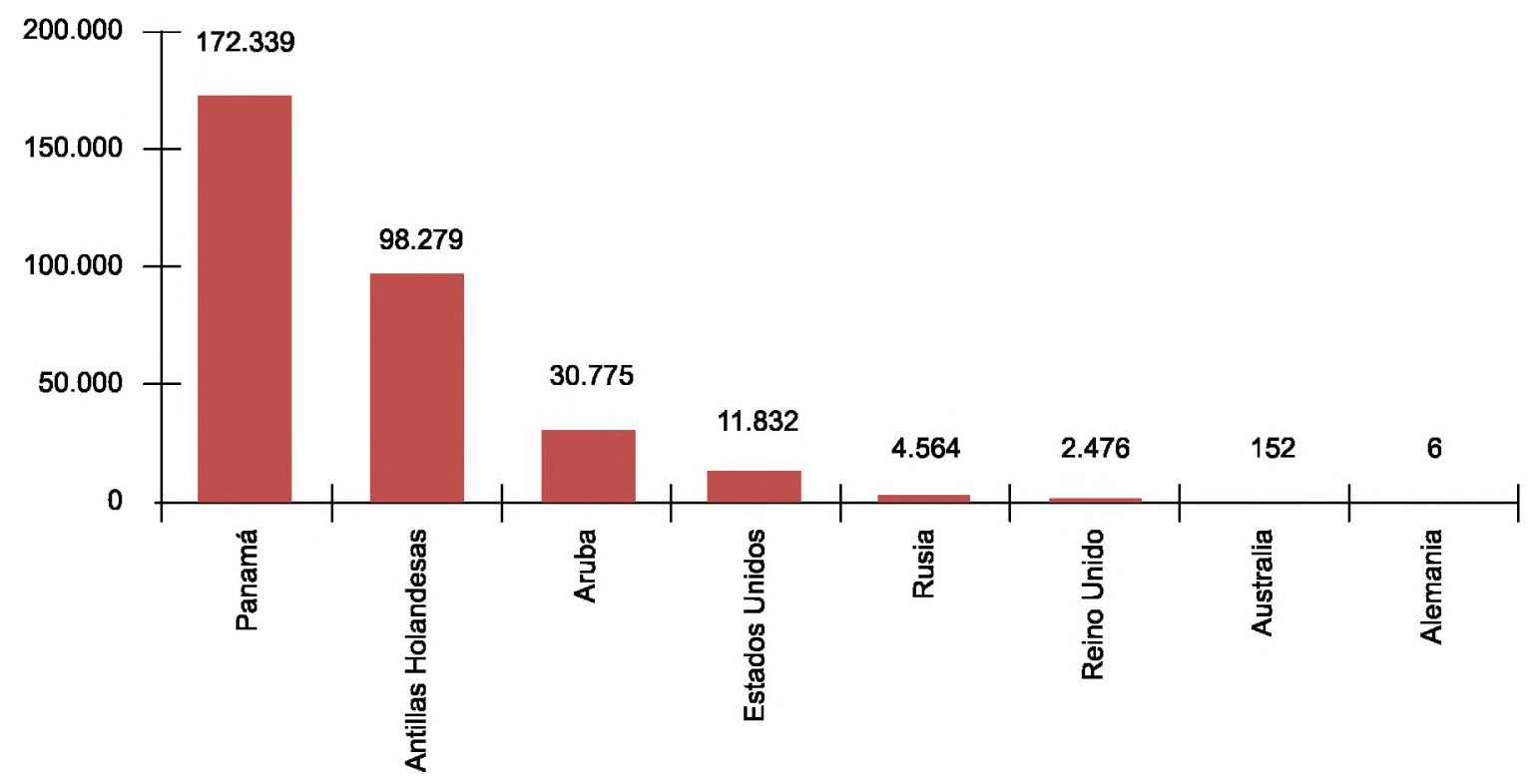

Lo ocurrido en la balanza comercial de las partidas en estudio, indica además que mientras las exportaciones aumentaron entre 2012 y 2013 en el $18.9 \%$, las importaciones lo hicieron en $314.7 \%$.

De otra parte se deduce de las cifras citadas que, entre las regiones productoras en Colombia, la que presentó un peor comportamiento en su balanza comercial fue Bogotá Cundinamarca, la cual obtuvo un incremento de sus importaciones del $136.5 \%$ entre 2012 y 2013, mientras que sus exportaciones, como ya se había, anotado crecieron en $17.7 \%$ en el mismo periodo.

La región Bogotá - Cundinamarca se consolidó como la principal región importadora de estos productos con el $42.7 \%$ (US\$ 259.202), los cuales fueron importados en su totalidad en Bogotá, seguida de Valle del Cauca (40.1\%), Antioquia (10.7\%) y Atlántico (6.5\%).

Las disparidades de crecimiento de importaciones y exportaciones, se pueden explicar en gran parte por el comportamiento de la oportunidad y la cantidad con que la cosecha del país salga al mercado. De acuerdo con esto, cuando la cosecha se retrasa en su salida, se estimulan las importaciones, que es el recurso al que acuden los comerciantes para mantener abastecido el mercado. También influye en este comportamiento del comercio exterior la calidad y cantidad de las respectivas cosechas, que inciden en el precio del producto. Además se asume el efecto cambiario, como en los años de referencia, cuando se presentaron tasas positivas de revaluación del peso que, indudablemente, afectaron negativamente el volumen de las exportaciones.

\section{CONCLUSIONES}

Las variedades de mora cultivadas en Colombia son diversas, sin embargo, la más conocida y con mayor opción para posicionarse en el mercado internacional, con fines de exportación, es la variedad Rubus glaucus Benth conocida como mora de Castilla. Ésta presenta como 
LÍNEA DE INVESTIGACIÓN: ECONOMIA INTERNACIONAL - NEGOCIOS INTERNACIONALES

atractivo especial en el mercado internacional, sus propiedades terapéuticas para diversas dolencias y enfermedades.

La superficie cultivada con mora a nivel nacional, ha aumentado consistentemente durante los últimos veinte años, pasando de un área de 3.167 hectáreas en 1992, a 11.986 hectáreas en 2013.

Aunque la productividad por hectárea no ha aumentado de manera significativa (pasó de un promedio nacional de 7.1 tons por hectárea en 1992 a 8.8 tons en 2013) el volumen total de producción si lo ha hecho, pasando de un total nacional de 22.476 tons, a 105.285 tons entre 1992 y 2013.

De los diez y siete departamentos con estadísticas de cultivos de mora, los tres departamentos con mayor producción son en su orden: Cundinamarca, Santander y Antioquia.
En cuanto a las potencialidades de mercados internacionales, Europa y particularmente España ofrecen buenas posibilidades.

No obstante sus limitaciones para realizar análisis dinámicos, la teoría convencional clásica y neoclásica sirve de marco referencial analítico, para ser aplicado al estudio tanto de las limitaciones como de las potencialidades de la mora colombiana para su inserción en los mercados internacionales. En efecto, conceptos como libertad de mercado, productividad, costos comparativos, ventaja comparativa, entre otros, ofrecen pertinencia para caracterizar la producción de mora en el país y para establecer sus ventajas o desventajas con relación a sus competidores.

Es bienvenida la participación de productos agrícolas colombianos en mercados externos, siempre y cuando ello contribuya a la generación de ingresos, a la creación de empleo y a mejorar la calidad de vida de los agricultores.

\section{REFERENCIAS}

Aguilar, S. (2011) "Caracterización molecular de Rubus spp., en el eje cafetero-Colombia". Tesis Magister en Ciencias, Biología Vegetal. Manizales: Universidad del Quindío, Universidad Tecnológica de Pereira, Universidad de Caldas.

Barrero L. (2009) "Caracterización, evaluación y producción de material limpio de mora con alto valor agregado", Corpoica, Ministerio de Agricultura y Desarrollo Rural. Bogotá.

Balassa, B. (1974) "Teoría de la Integración Económica" México. Uthea, Cámara de Comercio de Bogotá, Colombia.
Cámara de Comercio de Bogotá (2014). "Comercio Exterior: especial de fresa, frambuesa, zarzamora y mora". Año No. 3 Boletín No. 4.Recuperado de: http://camara.ccb. org.co/contenido/contenido. aspx?con ID=14039\&cat $\mid \mathrm{D}=942$

Castro, J. et al. (2012) "Diagnóstico y propuesta de negocio para el cultivo de mora orgánica en el municipio de El Colegio- Municipio saludable y polo de desarrollo", Universidad del Rosario, Bogotá.

CICO. (2009) "Perfiles de mercado-Mora". Centro de información e inteligencia Comercial. Ecuador.
Dai, J. (2007) "De los frutos rojos y sus beneficios para la salud: la mora".

Recuperado de: http:// consumergoldproducts. com.co/web/index.php/ nuestro-blog/70-de-los-frutos-rojos-y-sus-beneficios-para-la-salud-la-mora

Espinoza, N. (2011) "Evaluación morfoagronómica y caracterización molecular de la colección de mora de Corpoica y materiales del agricultor", tesis de grado, Universidad nacional de Colombia. Bogotá.

Franco G. \& Giraldo, C. (1998) "El cultivo de la mora". Corporación Colombiana de Investigación Agropecuaria, CORPOICA Regional 9. Pro- 
grama Nacional de Transferencia de Tecnologia Agropecuaria, PRONATTA. Colombia.

Grijalba, C. et al. (2010) "Rendimiento y calidad de la fruta en mora de castilla (Rubus glaucus Benth), con y sin espinas, cultivada en campo abierto en Cajicá, Cundinamarca, Colombia", Revista de Ciencias Básicas, Volumen 6, Número 1, Páginas 24-41, Universidad Militar Nueva Granada. Bogotá.

Heckscher, B. Ohlin, G.(1933). Interregional and International Trade. FCE. México.
Patel, A. et al. (2004) "Therapeutic constituents and actions of Rubus species". Current medical Chemistry. (11), 1501-1512.

Ricardo, D. (1984). "Principios de economía política y tributación", FCE, México, D,F.

Smith, A. (1958)"Investigación sobre la naturaleza y causas de la riqueza de las naciones, FCE, México D.F,.

Tinbergen, J. (1.968) "Hacia una economía mundial". Ed. Sagitario. Barcelona
Vidal L., Carlos D., \& Loaiza A. (2008) "Proyección de Colombia con relación a la exportación de pulpa de mora a Estados Unidos". Santiago de Cali.

Villareal, L. (2014) "Comercialización de mora de castilla producida en la provincia del Carchi sector Maldonado (Ecuador) y la demanda requerida en España", tesis de grado, Universidad del Carchi .Ecuador. 